\title{
POREZEKCINIS TIESIOSIOS ŽARNOS SINDROMAS
}

\author{
Viktorija Krunkaitienė, Skirmantas Krunkaitis \\ Lietuvos sveikatos mokslu universiteto Medicinos akademija
}

\begin{abstract}
Raktažodžiai: porezekcinis tiesiosios žarnos sindromas, tiesiosios žarnos vėžys, išmatų nelaikymas.
\end{abstract}

\section{Santrauka}

Tyrimo tikslas - apžvelgti porezekcinio sindromo (PRS) patofiziologiją, epidemiologiją ir ji galinčias sukelti priežastis, aptarti sindromo apibréžimą bei gydymo galimybes.

Tyrimui atlikti pasirinktas mokslinès literatūros analizès metodas. Šaltinių paieškai naudoti nurodyti raktažodžiai ir jų kombinacijos. Elektroninė literatūros paieška atlikta naudojantis PubMed (Medline), ScienceDirect, Cochrane Library elektroninèmis duomenų bazėmis. Buvo atrinkti viso teksto straipsniai anglų kalba. Tyrimo rezultatai parodè, kad tiesiosios žarnos vėžys yra viena dažniausių onkologinių patologijų, kurios radikalus gydymas yra daugiadisciplininis, įtraukiant ir chirurgini gydymą bei chemoterapines ir spindulines procedūras. Tai mažina pacientų mirtingumą, prailgina gyvenimo trukmę, tačiau gydymo eigoje dažnai išsivysto porezekcinis sindromas, kuris pastebimai sumažina gyvenimo kokybę. Porezekcinis tiesiosios žarnos sindromas yra tiesiosios žarnos véžio gydymo pasekmè, pasireiškianti grupe simptomų. Dažniausiai - išmatų nelaikymas, dažnas tuštinimasis, negalèjimas diferencijuoti dujų nuo išmatų. Rizikos veiksniai susiję su gydymo būdais. Dažniausi rizikos veiksniai yra adjuvantinè ir neoadjuvantinè chemoterapija, naviko lokalizacija tiesiojoje žarnoje - tai nulemia formuojamos anastomozès aukštị ir operacijos apimtị. PRS gydyti rekomenduojama pakopomis, pradedant nuo dietos pokyčių, medikamentinio gydymo, nepadejus neinvaziniams metodams, bandyti sfinkterių reabilitaciją grịžtamojo ryšio terapija. Galiausiai taikytina tibialinio ar sakralinio nervo stimuliacija, kritiniu atveju svarstytinas kolostomos suformavimas. Išvados. Statistiškai reikšmingu rizikos veiksniu laikytina neoadjuvantinè chemospindulinè terapija. Naviko lygis ir su tuo susijęs operacinio gydymo taktikos pasirinkimas daro įtaką PRS išsivystymui, tačiau tai nekoreguotinas rizikos veiksnys. Nepaisant įvairių prieinamų gydymo metodų, nèra atlikta plačių randomizuotų tyrimų ir metaanalizių, nėa aiškių, ịrodymais grịstų gydymo gairių, todèl tikslinga toliau tirti ir analizuoti porezekcinio tiesiosios žarnos sindromo gydymo galimybes.

\section{İvadas}

Porezekcinis tiesiosios žarnos sindromas (PRS) yra sunkiai apibrèžiamas ir iki šiol nèra bendro sutarimo, kokią būseną reikia laikyti PRS. Plačiausiai paplitusi nuostata, jog tai porezekcinè būklè, praejjus bent vieneriems metams po tiesiosios žarnos operacijos, pasireiškianti grupe simptomų: išmatų nelaikymas, tuštinimosi nereguliarumas, viduriu pūtimas, negebejjimas atskirti dujų nuo išmatų, gyvenimo kokybès sumažejimas ir kt. [1].

Storosios žarnos vėžys pasaulyje užima trečią vietą tarp onkologinių ligų. Lietuva - ne išimtis. Didžiają dalị sudaro tiesiosios žarnos navikai [2,3]. Pripažintas gydymo standartas yra daugiadisciplininis, taikant radikalų chirurginị gydymą bei spindulinę terapiją ir (ar) chemoterapiją. Šios gydymo dalys sudaro prielaidas išsivystyti porezekciniam sindromui, kuris pasireiškia 25-90 proc. pacientų [4-6]. Dažniausi literatūroje minimi rizikos veiksniai yra spindulinè terapija, chemoterapija, žema anastomozè ar jos nesandarumas bei komplikacijos, apsauginès (nukraunančios) stomos uždarymo laikas, visiška mezorektalinè ekscizija, lyginant su daline ir kiti $[5,7]$. Nèra atlikta pakankamai daug išsamių randomizuotų klinikinių tyrimų bei apžvalginių analizių, kurios patvirtintų ar atmestų rizikos veiksnių hipotezes.

Duomenų apie porezekcinị sindromą daugèja, tačiau ilgą laiką simptomų vertinimui buvo naudojami ịvairūs klausimynai bei priemonès, dèl to informacija labai heterogeniška ir vienareikšmių išvadų nèra. Nuo $2012 \mathrm{~m}$. pradetas naudoti ir plačiai pripažintas LARS score klausimynas, $2016 \mathrm{~m}$. patvirtinta jo lietuviškoji versija $[8,9]$. Pradejus tyrimuose naudoti standartizuotą klausimyną, susiformavo aplinkybès sistematizuoti rezultatus ir įvertinti didesnes kohortas. Ši problema būdinga ir sindromo gydymo algoritmų kūrimui - taikomi įvairūs gydymo metodai, tačiau nèra atlikta pakankamai informatyvių studijų ir randomizuotų tyrimų, kad būtų galima taikyti ịrodymais grisstus gydymo metodus. 
Tyrimo tikslas - apžvelgti porezekcinio sindromo (PRS) patofiziologiją, epidemiologiją ir ji galinčias sukelti priežastis; aptarti sindromo apibrèžimą bei gydymo galimybes.

\section{Tyrimo medžiaga ir metodai}

Tyrimui atlikti buvo analizuota aktuali mokslinè literatūra. Šaltinių paieškai pasitelkti raktažodžiai ir jų kombinacijos, naudojantis Būlio funkcijomis. Elektroninè literatūros paieška atlikta naudojantis PubMed (Medline), ScienceDirect, Cochrane Library elektroninėmis duomenų bazėmis. Buvo analizuoti atrinkti viso teksto straipsniai anglų kalba.

\section{Tyrimo rezultatai ir jų aptarimas}

Porezekcinio sindromo apibrèžimas ir epidemiologija. Porezekcinis sindromas - tai tiesiosios žarnos věžio gydymo pasekmé, pasireiškianti grupe simptomų. C. Keane ir kt. [1], sisteminèje literatūros apžvalgoje nagrinèję porezekcini sindromą, nustate, jog ši būklè 97 proc. pacientų pasireiškia išmatų nelaikymu, 80 proc. - dažnu tuštinimusi, 67 proc. staigiu noru tuštintis, 47 proc. - tuštinimosi disfunkcija, 34 proc. - negalejjimu diferencijuoti dujų nuo išmatų, 80 proc. - sumažejjusiu gyvenimo kokybès vertinimu. Tiesiosios žarnos gydymas pažeidžia ir urogenitalinę sistemą, sutrinka šlapimo pūslès funkcija, vyrams - erekcija, tačiau šie sutrikimai dažniausiai literatūroje nagrinejjami atskirai ir nèra priskiriami porezekcinio sindromo sąvokai [10].

Literatūroje pateikiama sindromo epidemiologija yra ivvairi - paplitimas aprašomas nuo 25 iki 90 proc. visų operuotų dèl tiesiosios žarnos vèžio [4-6]. A. Croese ir kt. [11] PRS paplitimo metaanalizėje apskaičiavo, kad vidutinis sunkaus porezekcinio sindromo pasireiškimo dažnis yra 42 proc. (95 proc. CI 34-48). Tiesiosios žarnos vėžio paplitimą ivvertinti nėra paprasta, nes dažniausiai statistika pateikiama nurodant kolorektalinio vėžio dažnį. Kolorektalinis vėžys dažniausiai nustatomas tiesiojoje žarnoje $[3,12]$. JAV kiekvienais metais nustatoma vidutiniškai 44180 tiesiosios žarnos vėžio atvejų $[3,12]$. Pradejjus taikyti daugiadisciplininị gydymą bei pažangią ankstyvają diagnostiką, pacientų išgyvenamumas nuo $1990 \mathrm{~m}$. stabiliai didejja 1,7 - 1,9 proc. kiekvienais metais [13]. Dideja sergamumas tiesiosios žarnos véžiu, ypač pacientų iki $50 \mathrm{~m}$. (kasmet padideja 3,9 proc.) [14]. Lietuvos higienos instituto duomenimis, $2017 \mathrm{~m}$. užfiksuoti 8345 kolorektalinio véžio atvejai [15]. Nacionalinio vėžio instituto duomenimis, tiesiosios žarnos véžys sudaro 43,2 proc., o 5 metų išgyvenamumas siekia 67 proc. [16,17]. Remiantis minètais duomenimis, galima daryti prielaidą, kad kiekvienais metais Lietuvoje susiformuoja reikšminga pacientų, sergančių porezekciniu sindromu, kohorta.

Tiesiosios žarnos vėžio gydymo principai. Tiesiosios žarnos vėžio gydymas priklauso nuo daugelio veiksnių ir yra daugiadisciplininis. Gydymo taktikos pasirinkimą didžiaja dalimi nulemia tumoro stadija pagal TNM klasifikaciją, aukštis tiesiojoje žarnoje, bei paciento operabilumas. Operacinio gydymo auksinis standartas yra totalinè tiesiosios žarnos ir mezorektumo ekscizija (TME). Operacijos metu aštriu būdu pašalinama $\mathrm{TŽ} \mathrm{ir} \mathrm{embriologiškai} \mathrm{giminingas} \mathrm{mezorektumas:}$ visas, jei naviko atstumas nuo $l$. dentata yra $0-10 \mathrm{~cm}$; arba dalis, jei tumoras yra $11-15 \mathrm{~cm}$ aukščiau $l$. dentata. Jei navikas yra apatiniame žarnos segmente 0-4 cm, atliekama tiesiosios žarnos ekstripacija [39]. Operacijos atliekamos keletu metodų: atviruoju būdu, laparoskopiškai, pastaruoju dešimtmečiu pradèta operuoti pasitelkiant robotines sistemas. Lyginant atvirają operaciją su laparoskopine, skirtumo tiriant mirtingumą ir mirštamumą nerasta, laparaskopinès pranašumas - geresni artimieji rezultatai: mažesnis pooperacinis skausmas, mažiau prarandama kraujo, tačiau ilgiau užtrunka operacija $[18,19]$. Robotine chirurgija turi pranašumų tais atvejais, kai priejjimas prie tiesiosios žarnos yra komplikuotas (siauras, vyriškos lyties dubuo), tačiau rezultatų atžvilgiu nèra vienareikšmių duomenų, ịodančių pranašumą [18,20]. Kartu su operaciniu gydymu taikoma ir neoadjuvantiné ar (ir) adjuvantinè spindulinè, chemospindulinè terapija. Kaip bendra taisyklè, papildomas gydymas atliekamas pacientams, sergantiems T3, T4 stadijos (pagal TNM klasifikaciją) tiesiosios žarnos vėžiu $[18,21]$.

Porezekcinio sindromo patofiziologija ir sąsaja su rizikos veiksniais. Tiesiosios žarnos tūrio ir prisitaikymo sumažējimas. Vienas plačiausiai diskutuojamų ir pripažintų patofiziologinių veiksnių yra tiesiosios žarnos tūrio bei prisitaikymo sumažejimas. TŽV gydyti dažniausiai atliekama TME. Kokybiškai atlikus TME, lieka tik keletas centimetrų TŽ aukščiau dantytosios linijos (1. dentata) [22]. Dèl minètos priežasties sumažejus žarnos tūriui ir prisitaikymo galimybėms, mažesnis kiekis išmatų sukelia norą tuštintis bei porezekcinio sindromo simptomus. Šią problemą bandoma išspręsti formuojant storosios žarnos rezervuarą (angl. Colonic J - pouch), tačiau funkciniai rezultatai nèra vienareikšmiai. C. Brown ir kt. [23] sisteminejje apžvalgoje pastebi, jog lyginant „tiesi, galas ị galą" ir „Colonic J - pouch“ anastomozes, pastaroji buvo pranašesnè, vertinant simptomus (viduriavimą, išmatų nelaikymą, dažną tuštinimąsi ir kt.). Pranašumas išlieka tik pirmuosius 18 pooperacinių mènesių. Tyrime buvo per mažai išgyvenusių pacientų, kad būtų galima ịvertinti anastomozių funkcinius pranašumus, praejjus daugiau kaip 18 mènesių.

Sfinkterių pažeidimas. Analinių sfinkterių struktūrinis ar (ir) inervacijos sutrikimas taip pat prisideda prie PRS išsivystymo. Vidinio sfinkterio veikla yra autonomiška, ramybès metu jis susitraukęs. Sutrikus funkcijai, pasireiškia nesąmoningas išmatų nelaikymas. Išorinio sfinkterio veikla 
yra valinga, jam sutrikus, pacientas sąmoningai negali kontroliuoti tuštinimosi. Ultragarso pagalba palyginus ikioperacinę ir pooperacinę sfinkterio būklę rasta, kad iki 18 proc. pacientų po priekinès apatinès rezekcijos (angl. low anterior resection) dvejus metus išliko vidinio sfinkterio pažeidimai ir PRS būdingi simptomai [24]. Atlikus anatominius imunohistocheminius tyrimus nustatyta, jog priekinè apatinė rezekcija pažeidžia vidini sfinkterị inervuojančius parasimpatinius nervus [25]. Yra įrodymų, jog tiesiosios žarnos véžio operacinis bei neoadjuvantinis gydymas sukelia vidinio sfinkterio ramybès tonuso sumažèjimą ir sumažina maksimalų išorinio sfinkterio gebejjimą susitraukti $[26,27]$.

Storosios žarnos judrumas. Literatūroje vienas iš pagrindinių minimų patofiziologinių veiksnių yra storosios žarnos judrumas (angl. colonic (dys)motility), apibūdinamas, kaip suaktyvejusi proksimalinès storosios žarnos veikla, kartu sutrikus distalinio galo inhibicijai $[5,27,28]$. Šis fenomenas pasireiškia dažnomis, trumpomis ir nereguliarioms naujai suformuoto rectum (angl. neorectum) peristaltikos bangomis. Klinikine išraiška - staigus noras tuštintis bei dažnas tuštinimasis [5, 28]. Yra duomenų, jog šio reiškinio priežastis susijusi su nusileidžiančiosios ir (ar) riestinès žarnos denervacija, atliekant operaciją [28,29]. Manoma, jog aktyvią peristaltiką sukelia ir tiesiosios žarnos pašalinimas, kuri normaliomis sąlygomis (grị̌tamojo ryšio principu) slopina proksimalinès storžarnès veiklą [27].

Rektoanalinis inhibicinis refleksas. Sutrikęs rektoanalinis inhibicinis refleksas (RAIR) taip pat sudaro prielaidas išsivystyti porezekciniam sindromui. RAIR pasireiškia vidinio analinio sfinkterio atsipalaidavimu kaip reakcija i tiesiosios žarnos spaudimą. RAIR nèra būtinas tuštinimosi procesui, tačiau jis padeda atskirti kietas išmatas nuo dujų [27,30,31]. Vertinant RAIR ikioperaciniu ir pooperaciniu laikotarpiu, atlikus balioninès anorektalinès manometrijos tyrimus nustatyta, kad didelio spaudimo zonos ilgis 3,11 $\mathrm{cm}$ (angl. high pressure zone), maksimalus slenkstinis tūris $181,8 \mathrm{ml}$ (angl. maximum threshold volume) bei mažesnis nei $4 \mathrm{~cm}$ TŽ likutis neužtikrins jos geros funkcijos po LAR [27,32]. Porezekcinio sindromo simptomus sukelia ir sumažeję̨s TŽ jautrumas mechaniniam bei terminiam dirgikliui. Jautrumą mažina aferentinių nervų skaidulų pažeidimas operacijos metu arba neoadjuvantiné spinduliné terapija [33].

Rizikos veiksniai. Rizikos veiksniai susiję su patofiziologiniais pokyčiais. Vienas dažniausiai diskutuojamų rizikos veiksnių yra adjuvantinè bei neoadjuvantinè spindulinè terapija, sukelianti audinių ir nervų pažeidimą. Randomizuotais tyrimais nustatyta, jog neoadjuvantinès terapijos mažesnis ir trumpalaikis, ir ilgalaikis nepageidaujamas poveikis, todèl šiuo metu ji taikoma dažniausiai [34], tačiau tai yra vienas iš pagrindinių PRS rizikos veiksnių $[6,7,35]$. Vèžio aukš- tis - žema naviko lokalizacija tiesiojoje žarnoje - taip pat laikytinas vienu iš labiausiai tikètinų rizikos veiksnių [6,36]. Anastomozės komplikacijos, ypač nesandarumas, nèra išimtis. Manoma, kad dèl uždegimo, peritonito ir susiformavusių sąaugų sumažèja neorectum tūris ir gebejjimas prisitaikyti [6]. Plačiai priimta nuomoné, jog nukraunančios stomos suformavimas mažina pooperacinị mirtingumą, susijusị su anastomozès komplikacijomis [37,38], tačiau ilgas stomos funkcionavimas bei vèlyvas jos uždarymas gali sukelti anastomozès stenozę, neorectum atrofiją ar kolitą, tokiu būdu paskatinant PRS išsivystymą [6,39].

Porezekcinio sindromo gydymo galimybės. Gydymo galimybės yra kelios, parenkamos pagal PRS pasireiškimo sunkumą. Esant lengvai sindromo formai, gydymą galima pradèti nuo dietos pakeitimo. Rekomenduojama valgyti maistą, turintị daugiau skaidulų, vengti produktų, galinčių suskystinti išmatas (kofeinas, citrusiniai vaisiai ir pan.). Kaip pirmo pasirinkimo taktika gali būti naudojami ir medikamentai, standartiniai vaistai nuo viduriavimo, tokie kaip loperamidas ar 5-HT3 antagonistai. Turima duomenų, jog klizmos naudojimas išsituštinti turi teigiamą poveikị PRS kontrolei [40;41]. Randomizuotame tyrime rasta, jog transanalinè irigacija, palyginta su pretibialinio nervo stimuliacija, reikšmingiau sumažino simptomus [42]. Nepadejus minètoms priemonèms ir jas taikant ilgiau kaip 6 mènesius, rekomenduojama bandyti dubens raumenų ir sfinkterių reabilitaciją grižtamojo ryšio terapija [43]. Galiausiai taikytina sakralinio nervo stimuliacija. Literatūroje nurodoma, kad sakralinio nervo stimuliacija gali pagerinti išmatų sulaikymą (75 proc. nelaikymo atvejų) [44]. Nepavykus suvaldyti simptomų ilgiau kaip dvejus metus, verta svarstyti dèl kolostomos sufomavimo. NICE gairèse rekomenduojamas pakopinis gydymas, visų pirma, po operacinio gydymo išleidžiant pacientus iš stacionaro, suprantamai informuoti apie galimus PRS simptomus, siekiant ankstyvosios diagnostikos. Nepavykus sindromo suvaldyti pirminiame lygyje, kreiptis dèl tolimesnio gydymo antriniame ar tretiniame lygyje.

\section{Išvados}

1. Daugelyje analizuotų straipsnių statistiškai reikšmingu rizikos veiksniu laikoma neoadjuvantinè chemospindulinè terapija.

2. Naviko lygis ir su tuo susijęs operacinio gydymo taktikos pasirinkimas turi ịtakos PRS išsivystymui, tačiau tai nekoreguotinas rizikos veiksnys.

3. Nepaisant ịvairių prieinamų gydymo metodų, nèra atlikta plačių randomizuotų tyrimų ir metaanalizių, dèl to aiškių, įrodymais grịstu gydymo gairiu nèra, todèl tikslinga toliau tirti ir analizuoti porezekcinio sindromo gydymo galimybes. 


\section{Literatūra}

1. Keane C, Wells C, Ogrady G, Bissett IP. Defining low anterior resection syndrome: a systematic review of the literature. Colorectal Disease 2017;19(8):713-22. https://doi.org/10.1111/codi.13767

2. Fitzmaurice C. Global, regional, and national cancer incidence, mortality, years of life lost, years lived with disability, and disability-adjusted life-years for 29 cancer groups, 2006 to 2016: A systematic analysis for the Global Burden of Disease study. Journal of Clinical Oncology 2018;36(15_suppl):1568. https://doi.org/10.1200/JCO.2018.36.15_suppl.1568

3. Global Cancer Observatory. Global Cancer Observatory. http:// gco.iarc.fr/

4. Martellucci J. Low Anterior Resection Syndrome. Diseases of the Colon \& Rectum 2016;59(1):79-82. https://doi.org/10.1097/DCR.0000000000000495

5. Bryant CL, Lunniss PJ, Knowles CH, Thaha MA, Chan CL. Anterior resection syndrome. Lancet Oncol 2012;13:403-8. https://doi.org/10.1016/S1470-2045(12)70236-X

6. Wells CI, Vather R, Chu MJJ, Robertson JP, Bissett IP. Anterior Resection Syndrome-A Risk Factor Analysis. Journal of Gastrointestinal Surgery 2014;19(2):350-9. https://doi.org/10.1007/s11605-014-2679-x

7. Ekkarat P, Boonpipattanapong T, Tantiphlachiva K, Sangkhathat S. Factors determining low anterior resection syndrome after rectal cancer resection: A study in Thai patients. Asian Journal of Surgery 2016;39(4):225-31.

https://doi.org/10.1016/j.asjsur.2015.07.003

8. Emmertsen KJ, Laurberg S. Low Anterior Resection Syndrome Score. Annals of Surgery 2012;255(5):922-8. https://doi.org/10.1097/SLA.0b013e31824f1c21

9. Samalavicius NE, Dulskas A, Lasinskas M, Smailyte G. Validity and reliability of a Lithuanian version of low anterior resection syndrome score. Techniques in Coloproctology 2016;20(4):215-20.

https://doi.org/10.1007/s10151-015-142

10. Dulskas A, Miliauskas P, Tikuisis R, Escalante R, Samalavicius NE. The functional results of radical rectal cancer surgery: review of the literature. Acta Chirurgica Belgica 2016;116(1):1-10.

https://doi.org/10.1080/00015458.2015.1136482

11. Croese AD, Lonie JM, Trollope AF, Vangaveti VN, Ho Y-H. A meta-analysis of the prevalence of Low Anterior Resection Syndrome and systematic review of risk factors. International Journal of Surgery 2018;56:234-41. https://doi.org/10.1016/j.ijsu.2018.06.031

12. Siegel RL, Miller KD, Jemal A. Cancer statistics, 2019. CA: A Cancer Journal for Clinicians 2019;69(1):7-34. https://doi.org/10.3322/caac.21551

13. Cronin KA, Lake AJ, Scott S, Sherman RL, Noone A-M, Howlader N, et al. Annual Report to the Nation on the Status of Cancer, part I: National cancer statistics. Cancer 2018;124(13):2785-800.

https://doi.org/10.1002/cncr.31551
14. Ahnen DJ, Wade SW, Jones WF, Sifri R, Silveiras JM, Greenamyer $\mathrm{J}$, et al. The Increasing Incidence of Young-Onset Colorectal Cancer: A Call to Action. Mayo Clinic Proceedings 2014;89(2):216-24. https://doi.org/10.1016/j.mayocp.2013.09.006

15. HI. Higienos instituto Sveikatos informacijos centras. 2017 http://sic.hi.lt/mapr1/

16. Statistiniai duomenys. Nacionalinis věžio institutas. https:// www.nvi.lt/naujausi-duomenys/

17. SEER Cancer Statistics Review, 1975-2015. SEER. https://seer. cancer.gov/csr/1975_2015/

18. Lichliter W. Techniques in Total Mesorectal Excision Surgery. Clinics in Colon and Rectal Surgery 2015;28(01):021-7. https://doi.org/10.1055/s-0035-1545066

19. Martínez-Pérez A, Carra MC, Brunetti F, De'Angelis N. Shortterm clinical outcomes of laparoscopic vs open rectal excision for rectal cancer: A systematic review and meta-analysis. World Journal of Gastroenterology 2017;23(44):7906-16.

https://doi.org/10.3748/wjg.v23.i44.7906

20. Meta-analysis of Robot-assisted Versus Laparoscopic Surgery for Rectal Cancer. In Vivo 2018;32(3) https://doi.org/10.21873/invivo.11283

21. Storosios (gaubtinès) žarnos piktybinio naviko, tiesiosios ir riestinès gaubtinès žarnos jungties piktybinio naviko ir tiesiosio žarnos piktybinio naviko diagnostikos ir gydymo tvarkos aprašas. Lietuvos Respublikos sveikatos apsaugos ministro 2018 m. birželio 6 d. įsakymas Nr. V-657. TAR, 2018-06-11, Nr. 9665. http://www.vlk.lt/

22. Ko TC. Low Anterior Resection - Total Mesorectal Excision. Atlas of General Surgical Techniques 2010:734-46. https://doi.org/10.1016/B978-0-7216-0398-8.50068-1

23. Brown CJ, Fenech D, Mcleod RS. Reconstructive Techniques After Rectal Resection for Rectal Cancer. Cochrane Database of Systematic Reviews 2008. https://doi.org/10.1002/14651858.CD006040.pub2

24. Farouk R, Duthie GS, Lee PWR, Monson JRT. Endosonographic evidence of injury to the internal anal sphincter after low anterior resection. Diseases of the Colon \& Rectum 1998;41(7):888-91.

https://doi.org/10.1007/BF02235373

25. Ishiyama G, Hinata N, Kinugasa Y, Murakami G, Fujimiya M. Nerves supplying the internal anal sphincter: an immunohistochemical study using donated elderly cadavers. Surgical and Radiologic Anatomy 2014;36(10):1033-42. https://doi.org/10.1007/s00276-014-1289-3

26. Williamson MER, Lewis WG, Finan PJ, Miller AS, Holdsworth PJ, Johnston D. Recovery of physiologic and clinical function after low anterior resection of the rectum for carcinoma. Diseases of the Colon \& Rectum 1995;38(4):411-8.

https://doi.org/10.1007/BF02054232

27. Berger N, Ludwig K, Ridolfi T. Low Anterior Resection Syndrome: Current Management and Future Directions. Clinics in Colon and Rectal Surgery 2016;29(03):239-45.

https://doi.org/10.1055/s-0036-1584500 
28. Emmertsen KJ, Bregendahl S, Fassov J, Krogh K, Laurberg $\mathrm{S}$. A hyperactive postprandial response in the neorectum - the clue to low anterior resection syndrome after total mesorectal excision surgery? Colorectal Disease 2013;15(10). https://doi.org/10.1111/codi.12360

29. Koda K, Saito N, Seike K, Shimizu K, Kosugi C, Miyazaki M. Denervation of the Neorectum as a Potential Cause of Defecatory Disorder Following Low Anterior Resection for Rectal Cancer. Diseases of the Colon \& Rectum 2005;48(2):210-7. https://doi.org/10.1007/s10350-004-0814-6

30. Ziv Y, Zbar A, Bar-Shavit Y, Igov I. Low anterior resection syndrome (LARS): cause and effect and reconstructive considerations. Techniques in Coloproctology 2012;17(2):151-62. https://doi.org/10.1007/s10151-012-0909-3

31. Kaur G, Gardiner A, Duthie GS. Rectoanal Reflex Parameters in Incontinence and Constipation. Diseases of the Colon \& Rectum 2002;45(7):928-33. https://doi.org/10.1007/s10350-004-6331-9

32. Ihnát P, Vávra P, Prokop J, Pelikán A, Rudinská LI, Penka I. Functional outcome of low rectal resection evaluated by anorectal manometry. ANZ Journal of Surgery 2017;88(6). https://doi.org/10.1111/ans.14207

33. Bregendahl S, Emmertsen KJ, Fassov J, Krogh K, Zhao J, Gregersen H, et al. Neorectal hyposensitivity after neoadjuvant therapy for rectal cancer. Radiotherapy and Oncology 2013;108(2):331-6.

https://doi.org/10.1016/j.radonc.2013.07.004

34. Sebag-Montefiore D, Stephens RJ, Steele R, Monson J, Grieve $\mathrm{R}$, Khanna S, et al. Preoperative radiotherapy versus selective postoperative chemoradiotherapy in patients with rectal cancer (MRC CR07 and NCIC-CTG C016): a multicentre, randomised trial. The Lancet 2009;373(9666):811-20. https://doi.org/10.1016/S0140-6736(09)60484-0

35. Bregendahl S, Emmertsen KJ, Lous J, Laurberg S. Bowel dysfunction after low anterior resection with and without neoadjuvant therapy for rectal cancer: a population-based cross-sectional study. Colorectal Disease 2013;

https://doi.org/10.1111/codi.12244

36. Martin ST, Heneghan HM, Winter DC. Systematic review of outcomes after intersphincteric resection for low rectal cancer. British Journal of Surgery 2012;99(5):603-12.

https://doi.org/10.1002/bjs.8677

37. Gu W-L, Wu S-W. Meta-analysis of defunctioning stoma in low anterior resection with total mesorectal excision for rectal cancer: evidence based on thirteen studies. World Journal of Surgical Oncology 2015;13(1):9. https://doi.org/10.1186/s12957-014-0417-1

38. Nash G. Re: Meta-analysis of defunctioning stomas in low anterior resection for rectal cancer Br J Surg (Br J Surg 2009;96:462-472). British Journal of Surgery 2009;96(9):1094. https://doi.org/10.1002/bjs.6794

39. Son DN. Relationship between diversion colitis and quality of life in rectal cancer. World Journal of Gastroenterology 2013;19(4):542. https://doi.org/10.3748/wjg.v19.i4.542

40. Martellucci J. Low anterior resection syndrome: a treatment algorithm. Dis Colon Rectum 2016;59:79-82 https://doi.org/10.1097/DCR.0000000000000495

41. McCutchan G, Hughes D, Davies Z, et al. Acceptability and benefit of rectal irrigation in patients with low anterior resection syndrome: a qualitative study. Colorectal Dis 2018;20(3):O76O84.

https://doi.org/10.1111/codi.13985

42. Enriquez-Navascues JM, Labaka-Arteaga I, Aguirre-Allende I, et al. A randomized trial comparing transanal irrigation and percutaneous tibial nerve stimulation in the management of low anterior resection syndrome. Colorectal Dis 2020;22(3):303-9. https://doi.org/10.1111/codi.14870

43. Liang Z, Ding W, Chen W, Wang Z, du P, Cui L. Therapeutic evaluation of biofeedback therapy in the treatment of anterior resection syndrome after sphincter-saving surgery for rectal cancer. Clin Colorectal Cancer 2016;15:e101-7.

https://doi.org/10.1016/j.clcc.2015.11.002

44. Croese AD, Whiting S, Vangaveti VN, Ho YH. Using sacral nerve modulation to improve continence and quality of life in patients suffering from low anterior resection syndrome. ANZ J Surg 2018;88:E787-91.

https://doi.org/10.1111/ans.14871

\section{LOW ANTERIOR RESECTION SYNDROME}

\section{Krunkaitienè, S. Krunkaitis}

Keywords: LARS, low anterior resection syndrome, rectal cancer, incontinence.

\section{Summary}

Low anterior resection syndrome (LARS) is a consequence of rectal cancer treatment that manifests with variety of symptoms such as: incontinence, urgency, inability to differentiate between stools and gas. Rectal cancer is one of the most common oncological pathologies; its radical treatment is multidisciplinary and involves surgical treatment as well as chemotherapy and radiotherapy. Treatment modalities have lowered mortality rate and have increased life expectancy. However, in most cases during the course of treatment LARS develops, therefore the quality of life decreases significantly. Risk factors are closely linked to treatment modalities. Literature puts an emphasis on adjuvant and neoadjuvant chemotherapy, localization of tumor- it determines the level of anastomosis and the extent of surgery. Management of LARS should be started from dietary changes, medications, if noninvasive options have no effect treatment should be escalated further. Biofeedback therapy and tibial or sacral nerve stimulation is an option. As a last resort to control the symptoms of LARS- colostomy can be considered. Despite multiple treatment options there are not enough randomized clinical trials done so that clinicians could follow evidence based algorithms.

Correspondence to: s.krunkaitis@gmail.com

Gauta 2021-05-18 